\title{
A far more ambitious species goal is needed for the Post-2020 Global Biodiversity Framework
}

\author{
Authors: Brooke A. Williams*1,2, James E.M. Watson ${ }^{1,2,4}$, Michelle S. Ward ${ }^{1,2}$, Nathalie Butt ${ }^{2,3}$, \\ Jeremy S. Simmonds ${ }^{1,2}$
}

\begin{abstract}
Affiliations:
${ }^{1}$ School of Earth and Environmental Sciences, University of Queensland, St Lucia 4072,

Australia.

${ }^{2}$ Centre for Biodiversity and Conservation Science, School of Biological Sciences, The

University of Queensland, St Lucia 4072, Queensland, Australia.

${ }^{3}$ School of Biological Sciences, The University of Queensland, St Lucia 4072, Queensland, Australia.

${ }^{4}$ Wildlife Conservation Society, Global Conservation Program, Bronx, NY 20460, USA.

*Correspondence to: brooke.williams@uq.edu.au
\end{abstract}




\begin{abstract}
Urgent action is required to 'bend the curve' on biodiversity loss. However, the 'species goal' (Goal B) unveiled in the recently released Zero Draft of the Post-2020 Global Biodiversity Framework (GBF) is inadequate for mobilizing conservation actions to achieve the outcomes required to halt and reverse species declines. Here we examine the limitations of the goal as presented in the Zero Draft and propose a more ambitious goal for species. The conservation community must ensure that the species goal of the GBF captures what is actually needed from a species perspective for the Post-2020 Framework to achieve its 2030 mission "to put biodiversity on a path to recovery for the benefit of planet and people", lest the mission be doomed from the start.
\end{abstract}

One Sentence Summary: No more extinctions alongside the stabilization and recovery of all species must be a key goal of the Post-2020 Global Biodiversity Framework. 


\section{Main Text:}

In 2010, Parties to the Convention on Biological Diversity (CBD) adopted the Strategic Plan for Biodiversity 2011-2020, and its 20 Aichi Biodiversity Targets, to trigger coordinated national and international conservation efforts in the face of ongoing biodiversity declines (1). In the intervening time, almost all indicators of biodiversity - and especially those relating to species' populations and species' extinction risk - have continued to trend downwards (2). We are now firmly in the midst of a biodiversity crisis. Yet, we also know that conservation actions, when well-planned and well implemented, can make a big, positive difference (3).

On the $6^{\text {th }}$ of January 2020, the Zero Draft of the Post-2020 Global Biodiversity Framework (hereafter, the 'draft framework') was released, presenting a brief window of opportunity for the global community to assess the potential strengths, weaknesses, and effectiveness of the draft framework (4). Where previously threatened species were the feature of a target (Aichi Target 12), in the draft framework, species have been elevated in importance to an overarching goal, Goal B. This states: "The percentage of species threatened with extinction is reduced by [X\%] and the abundance of species has increased on average by [X\%] by 2030 and by [X\%] by 2050."

We argue that the goal as written is ambiguous and will lead to perverse outcomes for threatened species conservation, is misaligned with other international agreements, and compromises the achievement of the 2030 Mission and 2050 Vision of the draft framework itself. While there is still time before the Post-2020 Global Biodiversity Framework is finalised, we discuss the three key problems with Goal B and, propose how it can be improved. 


\section{PROBLEM 1: ACCEPTING EXTINCTION AND EXACERBATING EXTINCTION RISK}

Aichi Target 12 took a clear and bold stance on extinction, stating that: "By 2020, the extinction of known threatened species has been prevented and their conservation status, particularly of those most in decline, has been improved and sustained". During the 10year period of nations acting to achieve Target 12 , species extinction rates were reduced when compared to previous decades (Fig. 1). But during this period at least 14 species went extinct, and the number of species threatened with extinction increased dramatically from 18,345 to 30,178 species (Fig. 1). While 51 species improved in their threat status (i.e., they were down-listed), more than six times that number (323 species) were up-listed (Fig. 2).

Its apparent successor, Goal B of the Post-2020 Global Biodiversity Framework, in spite of including stated quantifiable (percentage) targets, is a back down from Aichi Target 12 and may have unexpected implications. The new goal now conveys no explicit ambition to prevent further extinctions overall. In other words, contrary to Aichi Target 12, it implies that some extinctions are acceptable. Indeed, as currently written, Goal B could perversely be achieved by allowing species to go extinct, thus reducing the number of species 'threatened' with extinction. Further, Goal B could be achieved solely by downlisting a sufficient number of Vulnerable species to Near Threatened or Least Concern to meet the percentage target (number of species threatened with extinction reduced by $\mathrm{X} \%$ ), with (conceivably) no regard to the conservation status of those listed as Endangered or Critically Endangered. This may draw attention and critical resources away from these species more at risk of extinction, towards 'low-hanging fruit' (Vulnerable species), further imperilling Endangered and Critically Endangered species. 


\section{PROBLEM 2: ABUNDANCE OF WHAT?}

Increases in species' populations are fundamental to threatened species recovery. Further, an essential, but oft-overlooked facet of conservation is recovering and maintaining the populations of non-threatened species for the key role they play in the function of ecosystems. Population declines of those species that typically escape detailed conservation scrutiny - namely global invertebrate declines (5), and the 'biological annihilation' of common 'low concern' vertebrate populations $(6)$ - attest to the primacy of abundance as a key metric in any goal focused on species. However, the ambiguity that the 2010 Aichi targets were criticized for, has permeated the abundance component of Goal B.

Many questions remain open to interpretation of Goal B, for example: The abundance of which species should be increased? Where should population increases occur? What are the decisions and risks around quantifying this objective by using an average (percentage increase) - which populations would be allowed to decline while others were enhanced, to achieve the average increase called for in the goal? One interpretation is an invasive species that causes damage to its current non-native environment could increase by $100 \%$ (doubling its current population size) and the goal be achieved as it could contribute to the achievement of the abundance component of Goal B with its requirement for an increase of species (population) abundance "...on average by [X\%] by 2030 and by [X\%] by 2050". This perversity, and the unanswered questions posed, necessitate greater clarity around this component of the goal.

\section{PROBLEM 3: COMPROMISING OBJECTIVES}

Goal B is currently misaligned with broader international and societal goals. For example, Sustainable Development Goal 15 (Target 15.5) seeks to halt extinction and biodiversity 
loss (implicitly, stabilising populations and ultimately recovering threatened species) (7). A goal that allows for extinctions, and an increase in species extinction risk, also undermines the objectives of the United Nation's World Cultural And Natural Heritage convention by compromising values for which sites are recognized as World Heritage (geological and physiographical formations and precisely delineated areas which constitute the habitat of threatened species of animals and plants of outstanding universal value from the point of view of science or conservation) $(8)$.

Additionally, as currently written, Goal B is at odds with other goals and action targets captured in the draft framework. For example, a direction of resources towards Vulnerable species, precipitating unabated declines in Endangered and Critically Endangered species, will, in many cases, have adverse implications for the function of ecosystems (9) (compromising Goal A with its aim of net loss of ecosystem integrity). It could also result in less resources available for Endangered and Critically Endangered species conservation, whose costs of recovery generally increase with extinction risk (10). Extinction of species, the prevention of which is not captured in Goal B, would also clearly result in a loss of genetic diversity (11), contrary to Goal C. Reductions in populations and/or extinctions will also reduce the benefits from the use of genetic resources through potential missed opportunities for new medicines or increased scientific understanding (Goal E) (12). Increases in invasive species populations could also result in ecological degradation (13), compromising action target A3.

Perhaps most notably, Goal B is overtly misaligned with the draft framework's own 2030 Mission "To take urgent action across society to put biodiversity on a path to recovery for the benefit of the planet and people". Compromising Critically Endangered 
and Endangered species, and potentially losing some altogether, will not put biodiversity on "path to recovery". This also jeopardizes our ability to live "in harmony with nature", a key tenet of the draft framework's 2050 Vision.

\section{AN IMPROVED GOAL FOR SPECIES}

Ensuring species conservation is part of an overall goal, the addition of quantifiers, and the inclusion of abundance, which is vital for ecosystem functioning, are clearly necessary.

Nonetheless, given the limitations we point out, we propose several considerations for a revised, and more appropriate species goal. First, it is imperative that the goal takes a bold stance on species extinctions (as did Aichi Target 12) and calls for zero extinctions after 2020. Even under Aichi Target 12, extinctions occurred (Fig. 1) but it is also clear they were reduced when compared to previous decades. We argue that any relaxation on the expectations of countries to prevent extinctions is not an adequate response to the biodiversity crisis. Second, it should be stipulated the that the status of all listed threatened species (as of 2020) will demonstrably improve, by 2050, with quantifiable targets for the number (or percentage) of species down-listed to a less severe threat category by 2030 embedded in the goal, as a means by which to check whether we are "on the path to recovery".

Crucially, to avoid the perversity of the current wording, any such quantifiable targets, for down-listings should apply to all threat categories: that is, $\mathrm{X} \%$ of Critically Endangered, Endangered, and Vulnerable species, respectively, are down-listed by 2030. We propose $33.3 \%$ as a bare minimum percentage, as this is a third of the way through the 30-year time period (towards the 2050 Vision). Importantly, this focused effort to down-list a subset of threatened should not increase the extinction risk of the other $66.7 \%$ of threatened species during the period 2020-2030, by, for example, diverting resources. 
Maintaining populations of all, and increasing those of some, is vital to get us on the desired path.

The abundance component of the goal is open to interpretation and requires specificity. At the very least, it should be specified that maintenance of, and where required, increases in, population sizes of species occur only within their native range, and that such population maintenance/increases apply not only to threatened species, but those that are 'Near Threatened', 'Least Concern' and 'Data Deficient'. These should be recovered and managed at levels that contribute to ecosystem function and the provision of key services.

Therefore, an improved species goal may read "No species will go extinct or increase in extinction risk (be up-listed), after 2020. The status of all threatened species (listed as 'Critically Endangered', 'Endangered' and 'Vulnerable') will improve (downlisted to 'Near Threatened' or 'Least Concern') by 2050, with demonstrable evidence of improvement (33.3\% of all species within each category down-listed) by 2030. No species will be Data Deficient by 2050.”

This revised goal takes a firm stance on extinction ("No species will go extinct") and calls for the maintenance of all species populations ("No species will... increase in extinction risk (be up-listed), after 2020"). In other words, it calls on nations of the world to accept no more extinctions, and to keep our non-threatened biodiversity just that, nonthreatened. It embeds and allows for the tracking of the recovery of threatened species populations "The status of all threatened species (listed as 'Critically Endangered', 'Endangered' and 'Vulnerable') will improve (down-listed to "Near Threatened" or "Least Concern”) by 2050”, where this improvement is equal across all threat categories. 
Finally, it calls for Data Deficient species to be assessed and for them to receive a conservation status, a gap in the current goal which risks the ongoing lack of attention these species receive in conservation legislation and management (14). Tracking the progress towards achieving the all of quantifiable sub-components of this proposed goal is possible using the International Union for Conservation of Nature (IUCN) Red List, a globally recognised and standardized approach for assessing species threat status (15).

The goal we propose is ambitious, strips away ambiguity, is easily interpretable, and comprises quantifiable sub-components that nations can transparently measure their progress against. If we want to be on a path to recovery by 2030, and living in harmony with nature in 2050 , then in 2020, we must take decisive action for biodiversity. A clear, ambitious goal for species is fundamental to these efforts. 


\section{References:}

1. Secretariat of the Convention on Biological Diversity, Strategic Plan for Biodiversity 2011-2020 and the Aichi Targets (Secretariat of the Convention on Biological Diversity) (2011), (available at https://www.cbd.int/sp/).

2. G. M. Mace, M. Barrett, N. D. Burgess, S. E. Cornell, R. Freeman, M. Grooten, A. Purvis, Aiming higher to bend the curve of biodiversity loss. Nat. Sustain. 1, 448-451 (2018).

3. M. J. Monroe, S. H. M. Butchart, A. O. Mooers, F. Bokma, The dynamics underlying avian extinction trajectories forecast a wave of extinctions. Biol. Lett. 15, 20190633 (2019).

4. Secretariat of the Convention on Biological Diversity, Zero Draft of the Post-2020 Global Biodiversity Framework (2020) (available at https://www.cbd.int/article/2020-01-10-1902-38).

5. F. Sánchez-Bayo, K. A. G. Wyckhuys, Worldwide decline of the entomofauna: A review of its drivers. Biol. Conserv. 232, 8-27 (2019).

6. G. Ceballos, P. R. Ehrlich, R. Dirzo, Biological annihilation via the ongoing sixth mass extinction signaled by vertebrate population losses and declines. Proc. Natl. Acad. Sci. 114, E6089-E6096 (2017).

7. United Nations Educational Scientific And Cultural Organisation, Transforming our world: The 2030 agenda for sustainable development. Gen. Assem. 70 Sess. (2015) (available at https://www.unfpa.org/resources/transforming-our-world-2030-agendasustainable-development).

8. United Nations Educational Scientific And Cultural Organisation, Convention concerning the protection of the world cultural and natural heritage. World Herit. Comm. (1972) (available at https://whc.unesco.org/archive/convention-en.pdf).

9. A. Estrada, P. A. Garber, A. B. Rylands, C. Roos, E. Fernandez-Duque, A. Di Fiore, K. A.-I. Nekaris, V. Nijman, E. W. Heymann, J. E. Lambert, Impending extinction crisis of the world's primates: Why primates matter. Sci. Adv. 3, e1600946 (2017).

10. H. B. Wilson, L. N. Joseph, A. L. Moore, H. P. Possingham, When should we save the most endangered species? Ecol. Lett. 14, 886-890 (2011).

11. D. Spielman, B. W. Brook, R. Frankham, Most species are not driven to extinction before genetic factors impact them. Proc. Natl. Acad. Sci. 101, 15261-15264 (2004).

12. G. W. Luck, G. C. Daily, P. R. Ehrlich, Population diversity and ecosystem services. Trends Ecol. Evol. 18, 331-336 (2003).

13. J. R. Walsh, S. R. Carpenter, M. J. Vander Zanden, Invasive species triggers a massive loss of ecosystem services through a trophic cascade. Proc. Natl. Acad. Sci. 113, 40814085 (2016).

14. S. D. Howard, D. P. Bickford, Amphibians over the edge: silent extinction risk of Data Deficient species. Divers. Distrib. 20, 837-846 (2014).

15. International Union for Conservation of Nature, The IUCN red list of threatened species. Int. Union Conserv. Nat. Nat. Resour. (2020), (available at https://www.iucnredlist.org/ ). 
Acknowledgments: This research was supported by an Australian Government Research Training Program Scholarship and the Wildlife Conservation Society; Funding: None to declare; Author contributions: J.E.M.W conceived the idea. B.A.W. led the writing of the manuscript with input from J.S.S, J.E.M.W, M.S.W, and N.B; Competing interests: Authors declare no competing interests; and Data and materials availability: All data used to create figures can be downloaded from https://www.iucnredlist.org/resources/summarystatistics\#Summary\%20Tables. 


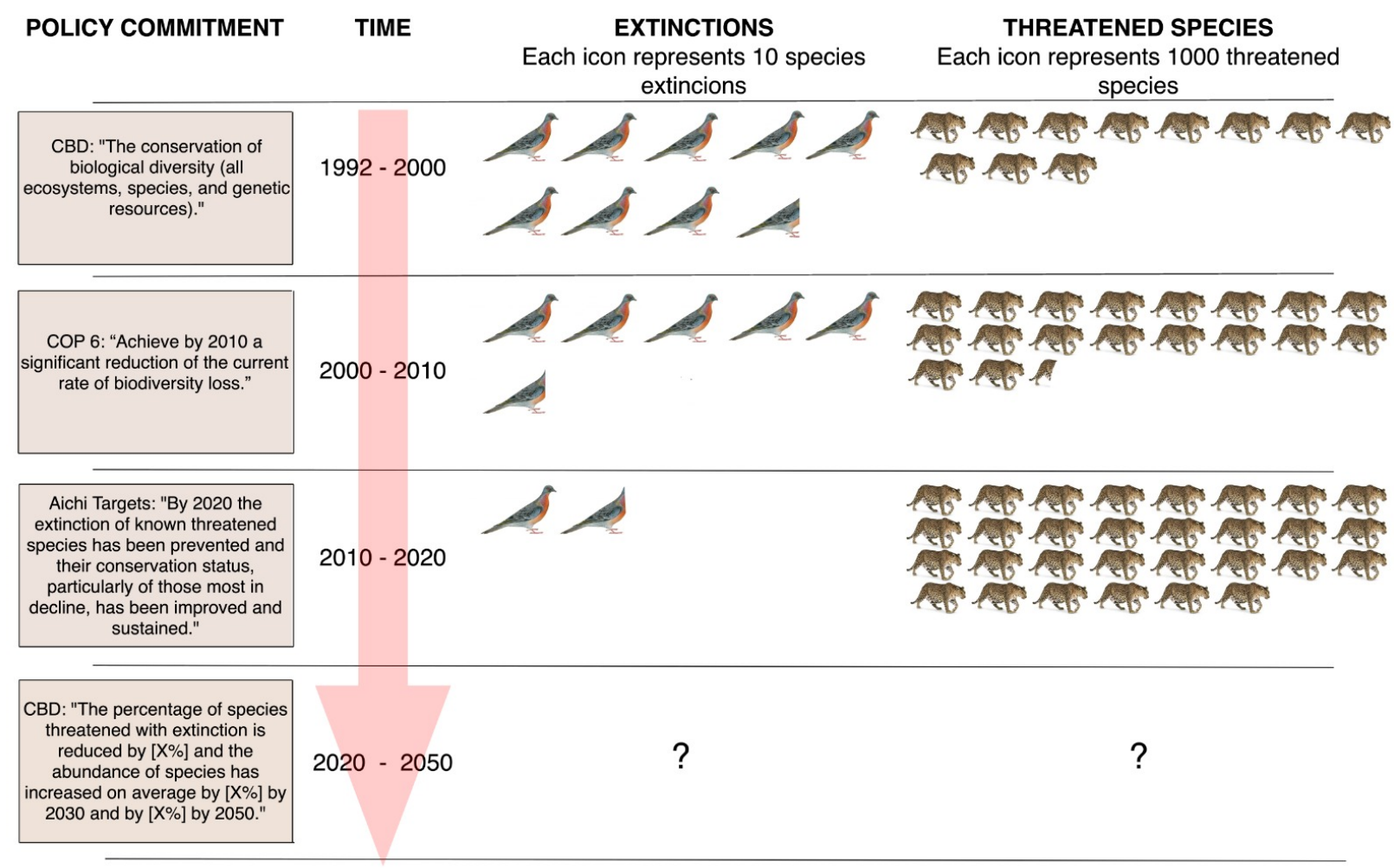

Fig. 1. Species extinctions and species threatened with extinction (Vulnerable, Endangered and Critically Endangered) as listed by the International Union for Conservation of Nature Red List (15) within each time period where a policy commitment relating to species conservation has been undertaken by the Convention on Biological Diversity. There has been a clear decline in extinctions over time, but an increase in species threatened with extinction over time since 1992. 

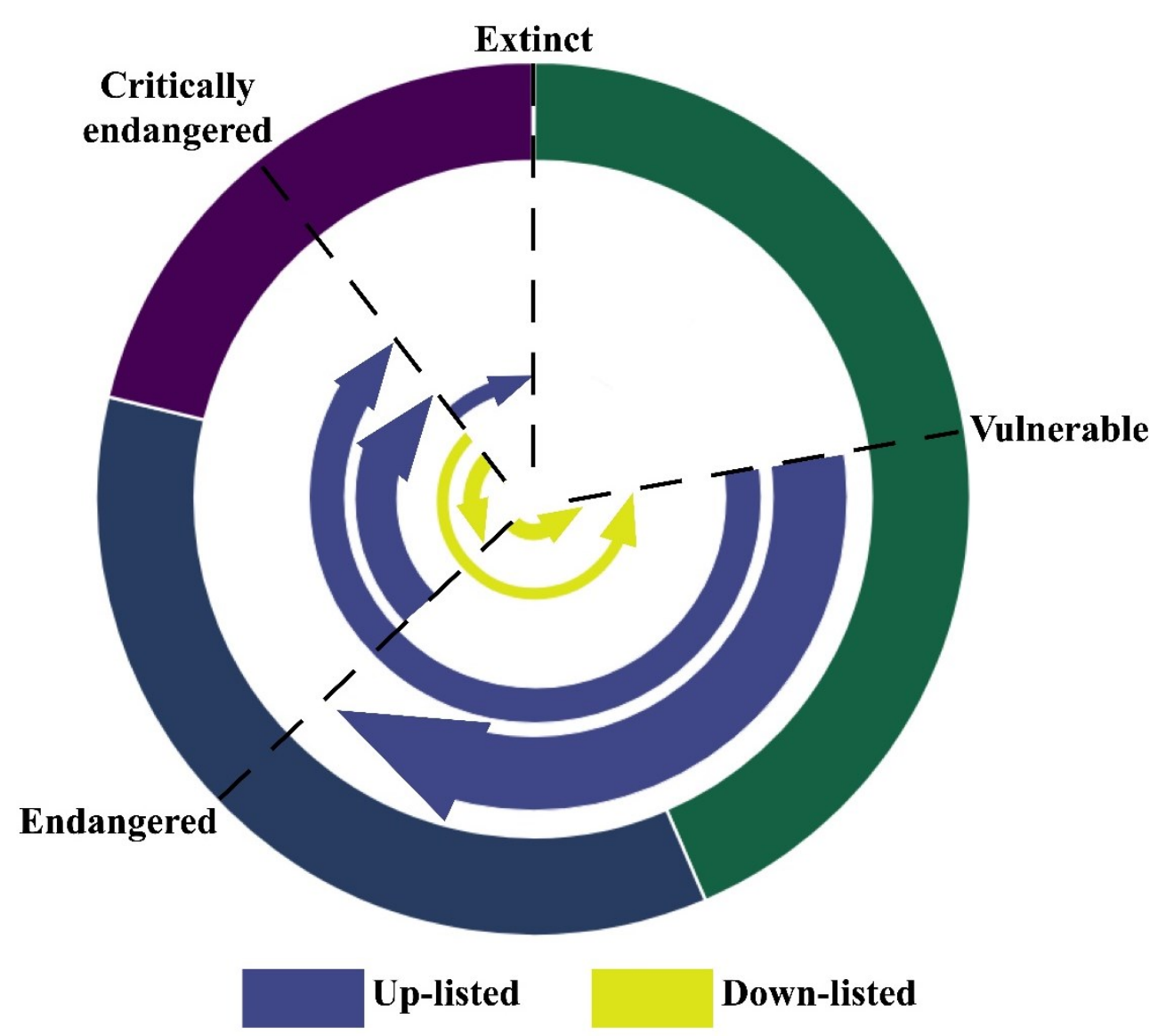

Down-listed

Fig. 2. As of 2020, there are many more International Union for Conservation of Nature listed Vulnerable species $(13,136)$ than Endangered $(10,629)$, Critically Endangered $(6,413)$ or Extinct (22). Six times as many species have been moved from Vulnerable or Endangered to a more severe threat status (Endangered, Critically Endangered, or Extinct) $(n=323)$ than have been down-listed to Vulnerable or Endangered $(n=51)$ since the Strategic Plan for Biodiversity 20112020, and its 20 Aichi Biodiversity Targets came into force in January 2011. The relative number of species that have been up-listed or down-listed is represented by line thickness and arrow head size, as well as being in order from most species (outer line) to least species (inner line). Data represents only genuine up-listing or down-listings, that is, actual increases/decreases of threats leading to population change rather than the availability of new data or updated categorisations. 